\title{
Investigationon Hardness or Heat Treated ASSAB Tool Steels
}

\author{
Alias Mohd*, Nurul Hazwani and Nor Bahiyah Baba \\ Faculty of Manufacturing Engineering Technology, TATI University College, Kijal, Kemaman, Terengganu, \\ Malaysia; aliasmohd@tatiuc.edu.my,wanie_achik@yahoo.com, bahiyah@tatiuc.edu.my
}

\begin{abstract}
Background/Objectives: This paper presents experimental investigation on the hardness for ASSAB tool steels, XW-5 and XW-42 in heat treatment processes. The experiment was carried out by considering hardening temperature, quenching oil and tempering temperature as parameters at various levels. Methods/Statistical Analysis: The parameters that will influence from the value has been concluded into a Taguchi Orthogonal Array. Findings: The result was analyzed using the Minitab 15 software. Results were compared for XW- 5 and XW-42 from the experiment. XW42 exhibits the better and harder due to all values are significant. Applications/Improvements: It is observed that different heat treatment processes significantly improves the mechanical properties such as hardness, toughness and microstructure of ASSAB tool steels.
\end{abstract}

Keywords: Hardness, Heat Treatment, XW-5 Steel, XW-42 Steel

\section{Introduction}

Research for tool steel materials with high wear resistance at high temperature is the continuous process. ${ }^{1}$. The main characteristics of tool steel including better machinability, good dimensional stability in hardening and also a good combination of high surface hardness and toughness after hardening and tempering ${ }^{2}$. These characteristics combine and give steel suitable for the manufacture of tooling with good tool-life and high production economy. XW-5 features are a high-carbon and high-chromium alloy tool steel. It has good wear resistance and size ability after heat. Pure steel quality due to vacuum degas refining treatment, treatment and is suitable for making long-life highprecision cold-work dies ${ }^{3}$. The XW-5 except for the scope of application, the usually thick and can be used in the cutting load on the forming mold. It is also suitable for the blanking dies and punching dies not thicker than $6 \mathrm{~mm}$. Then, uses for multiple types of plastic blades of grinder and durable mowing blades. XW-5 is suitable for multiple types of drawing dies and cold extrusion dies too.

XW-42 features are a molybdenum, vanadium highcarbon and high chrome alloy tool steel. The characteristics are high wear resistance, high compressive strength, high surface hardness after hardening, excellent overall harden ability, when hardened, excellent stability and excellent resistance to temper softening. The primary purpose for $\mathrm{XW}-42$ is often recommended as a good wear resistance necessary and appropriate toughness of the tooling. In the tool steel annealing is carried out to receive more fine and homogeneous distribution of cementite particles which influence the final dimension and properties of heattreated tools.

Heat treatment operation is a means of controlled heating and cooling of materials in order to effect changes in their mechanical properties. It was however known that mechanical properties of steel were strongly connected to their microstructure obtained after heat treatments which are performed to achieve good hardened and tensile strength with sufficient ductility ${ }^{5-7}$. Tempering reduces the hardness, residual stress but increases the ductility ${ }^{8-10}$.

\section{Experimental Works}

The XW- 5 and XW- 42 are high carbon composition steels as shown in Table 1 . The specimen size of $30 \mathrm{~mm} \times 30 \mathrm{~mm}$ $\mathrm{x} 10 \mathrm{~mm}$ was prepared. By using Taguchi orthogonal array for three parameters and three levels, the experiments works are arranged ${ }^{11}$. 
Table 1. Chemical composition for ASSAB steels

\begin{tabular}{lccccccc}
\hline Grade & C & Mn & Cr & Mo & V & W & Si \\
\hline XW-5 & 2.05 & 0.8 & 12.7 & - & - & 1.1 & 0.30 \\
XW-42 & 1.55 & 0.4 & 11.6 & 0.8 & 0.9 & - & 0.30 \\
\hline
\end{tabular}

The experiment's standard layout is a 3 level OA L9 $\left(3^{3}\right)$ for factor is listed as shown in Table 3. All the parameters and levels used are arranged accordingly to Table 2 . The interaction between parameters was neglected.

Table 2. Experimental layout using L9 (33) orthogonal array

\begin{tabular}{llll}
\hline Experiments & \multicolumn{3}{c}{ Heat Treatment Parameters } \\
\cline { 2 - 4 } & A & B & C \\
\hline 1 & 1 & 1 & 1 \\
2 & 1 & 2 & 2 \\
3 & 1 & 3 & 3 \\
4 & 2 & 1 & 2 \\
5 & 2 & 2 & 3 \\
6 & 2 & 3 & 1 \\
7 & 3 & 1 & 3 \\
8 & 3 & 2 & 1 \\
9 & 3 & 3 & 2 \\
\hline
\end{tabular}

Table 3 gives the factors and their levels. The process parameters are hardening temperature, quenching oil time and tempering temperature. The standard parameter values of hardening temperature for XW- 5 and $\mathrm{XW}-42$ are $990^{\circ} \mathrm{C}$, $995^{\circ} \mathrm{C}$ and $1000^{\circ} \mathrm{C}$ respectively. The time used for quenching oil process was 10 minutes, 20 minutes and 30 minutes and the tempering temperature $200^{\circ} \mathrm{C}, 250^{\circ} \mathrm{C}$ and $520^{\circ} \mathrm{C}$ respectively.

Table 3. Heat treatment parameters and their level

\section{Heat Treatment Parameters}

$\begin{array}{lccc}\text { Experiments } & \begin{array}{c}\text { Hardening } \\ \text { Temp. (A), } \\ { }^{\circ} \mathrm{C}\end{array} & \begin{array}{c}\text { Quenching } \\ \text { Oil (B), } \\ \text { min. }\end{array} & \begin{array}{c}\text { Tempering } \\ \text { Temp. (C) } \\ 1\end{array}{ }^{\circ} \text { C } \\ 2 & 990 & 10 & 200 \\ 3 & 995 & 20 & 250 \\ & 1000 & 30 & 5\end{array}$

All experiments were carried out using a solo heat treatment machine before putting to hardness checking as a result. The hardness measured according to the Hardness Rockwell test C (HRC). The Rockwell test uses a small steel sphere for the indenter of a diamond cone for harder materials. It differs from the Brinell hardness testing technique in that it measures the depth of penetration by the indenter.

Hardness measurements are read off a gauge, which is effectively a calibrated depth gauge. Advantages of the Rockwell hardness method include the direct Rockwell hardness number readout and rapid testing time.

\section{Results and Discussion}

The experimental resultsof hardness test at the different level of parameters are shown in Table 4. The range of hardness test on both materials XW-5 and XW- 42 was not varied much between 60.14-64.81 and 54.09-68.60.

Table 4. The hardness results for XW-5

\begin{tabular}{lccccc}
\hline Expts & \multicolumn{3}{c}{ Heat Treatment } & \multicolumn{2}{c}{ Hardness Result/ } \\
& \multicolumn{3}{c}{ Parameters } & \multicolumn{2}{c}{ HRC } \\
\cline { 2 - 6 } & A $\left({ }^{\circ} \mathrm{C}\right)$ & B (min) & C $\left({ }^{\circ} \mathrm{C}\right)$ & XW-5 & XW-42 \\
\hline 1 & 990 & 10 & 200 & 63.82 & 54.09 \\
2 & 990 & 20 & 250 & 64.81 & 65.08 \\
3 & 990 & 30 & 520 & 61.42 & 70.97 \\
4 & 995 & 10 & 250 & 61.34 & 68.60 \\
5 & 995 & 20 & 520 & 61.83 & 77.34 \\
6 & 995 & 30 & 200 & 60.14 & 71.30 \\
7 & 1000 & 10 & 520 & 62.55 & 61.29 \\
8 & 1000 & 20 & 200 & 64.02 & 62.27 \\
9 & 1000 & 30 & 250 & 60.85 & 66.20 \\
\hline
\end{tabular}

Figure 1 shows the result of Linear Model Analysis for main effect plot for means against hardening, quenching and tempering parameters for XW-5 steel. In this case, the graph shows that the hardening and quenching have significant effect compared to tempering. This indicates that the hardness data successfully achieves and give influence to this experiment.

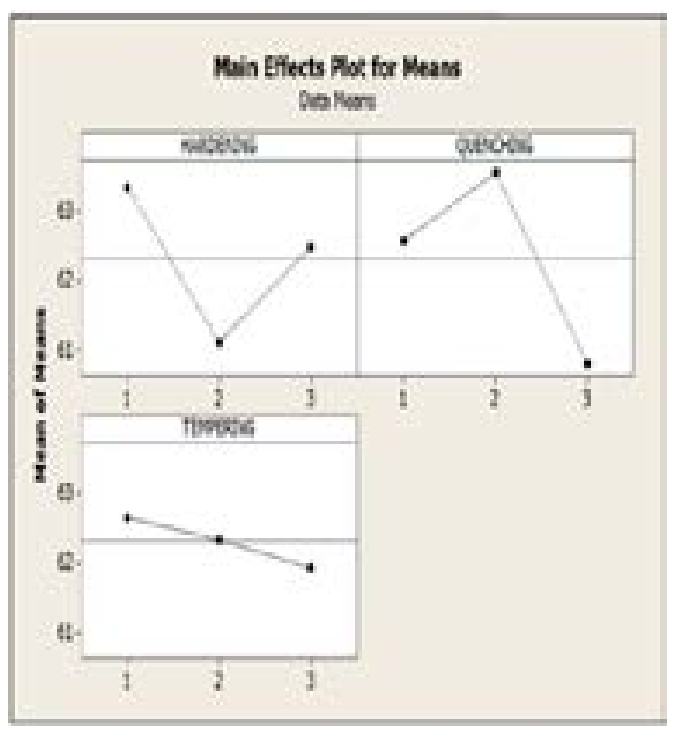

Figure 1. The main effects plotsformeans (XW-5). 
The final optimal process parameter setting was confirmed by the graph of Minitab 15 software. The Rockwell hardness was used to determine the value of hardness after the heat treatment process. Figure 1 determines whether or not the hardness is acceptable for XW-5 steel.

Based on the plots in Figure 1, the difference between the maximum and minimum values in the main effect plot was analyzed by Minitab 15 software. The effective value for hardening parameter is 2.24 (63.35-61.10) whereas quenching is 2.75 (63.55-60.80). On the other hand, tempering effect is not significant.

The data and results calculated by Minitab 15 software were simplified in Table 5. Analysis Of Variance (ANOVA) table comes out with P-value. Statistically, if the P-value is less than 0.05 $(\mathrm{P}<0.05)$, the parameter is said to be significant. This is because the confidence level that is used in the experiment is $95 \%$. The most significant value in this experiment is quenching (0.015). The second rank is hardening (0.023). The insignificant result is tempering $(0.180)$ whereas the value $\mathrm{P}>0.05$. From this discussion, the quenching and hardness value are significant because both of these factors give large effect to the hardness of both ASSAB steels.

Table 5. ANOVA for means (XW-5)

\begin{tabular}{lcccccc}
\hline \multicolumn{7}{c}{ Analysis of Variance for Means } \\
\hline Source & DF & Seq SS & Adj SS & Adj MS & F & P \\
HARDEN- & 2 & 7.6652 & 7.6652 & 3.83262 & 43.36 & 0.023 \\
ING & & & & & & \\
QUENCH- & 2 & 11.6305 & 11.6305 & 5.81525 & 65.79 & 0.015 \\
ING & & & & & & \\
TEMPERING & 2 & 0.8048 & 0.8048 & 0.40240 & 4.55 & 0.180 \\
$\begin{array}{l}\text { Residual } \\
\text { Error }\end{array}$ & 2 & 0.1768 & 0.1768 & 0.08839 & & \\
\hline Total & $\mathbf{8}$ & $\mathbf{2 0 . 2 7 7 3}$ & & & & \\
\hline
\end{tabular}

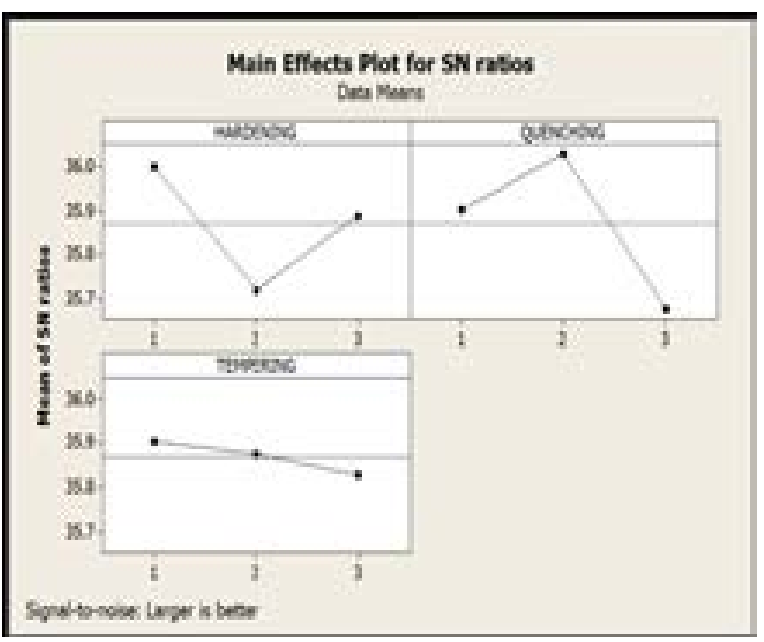

Figure 2. The main effects plot for $\mathrm{SN}$ ratios (XW-5).
Figure 2 shows the main effect plot for SN ratios. The experiment was set to larger the better signal-to-noise ratio. The optimum condition will be achieved at hardening level 1 , quenching at level 2 and tempering at level 1 . Since previously, the $\mathrm{P}$-value analysis indicated tempering is not significant. The true optimum condition is quenched at level 2, which followed by hardening at level 1 .

The main effect plot for means for XW-42 is given in Figure 3. The hardening seemed to give high effect to the experiment which followed by quenching. Lastly, the tempering effect is the least compared to the other two. From the figure, the hardening and quenching give higher effect than tempering parameter.

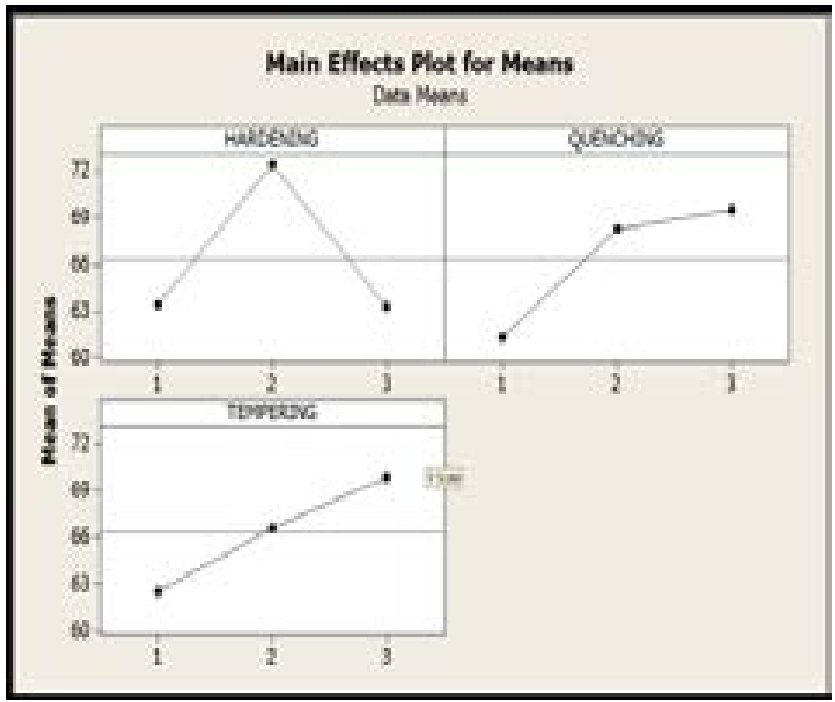

Figure 3. The main effects plot for means (XW-42).

Similar to the XW-5, the data collection gets effect's value from the plot by getting the difference between the maximum and minimum values. For tool steel XW-42, the effective value for parameter hardening is (72.41-63.25 = 9.16). The next plot graph is quenching $(69.49-61.33=8.16)$ and lastly, empering plot graph is $(69.87-62.55=7.31)$.

The ANOVA table for XW-42 is given in Table 6. From the data and results are calculated based on the $95 \%$ confidence level $(\mathrm{P}<0.05)$. The most significant value in this experiment is hardening with the $\mathrm{P}$-value 0.023 . The second rank is quenched with 0.033 . Lastly is tempered with P-value 0.046 . Therefore, all parameters are significant because of $\mathrm{P}<$ 0.05 . In other words, all parameters are significantly affecting the hardness of the heat treated ASSAB XW-42 steel. 
Table 6. ANOVA for means (XW-42)

\begin{tabular}{lcccccc}
\hline \multicolumn{7}{c}{ Analysis of Variance for Means } \\
\hline Source & DF & Seq SS & Adj SS & Adj MS & F & P \\
HARDEN- & 2 & 165.444 & 165.444 & 82.722 & 42.44 & 0.023 \\
ING & & & & & & \\
$\begin{array}{l}\text { QUENCH- } \\
\text { ING }\end{array}$ & 2 & 115.842 & 115.842 & 57.921 & 29.72 & 0.033 \\
$\begin{array}{l}\text { TEMPER- } \\
\text { ING }\end{array}$ & 2 & 80.604 & 80.604 & 40.302 & 20.68 & 0.046 \\
$\begin{array}{l}\text { Residual } \\
\text { Error }\end{array}$ & 2 & 3.898 & 3.898 & 1.949 & & \\
\hline Total & 8 & 365.787 & & & & \\
\hline
\end{tabular}

Figure 4 shows the main effects plot for SN ratios. The optimum condition for hardening is at level 2. Then, the quenching at level 3 and lastly, the tempering at level 3. Thus, the optimization process will be achieved at hardening level 1, quenching level 3 and tempering level 3.

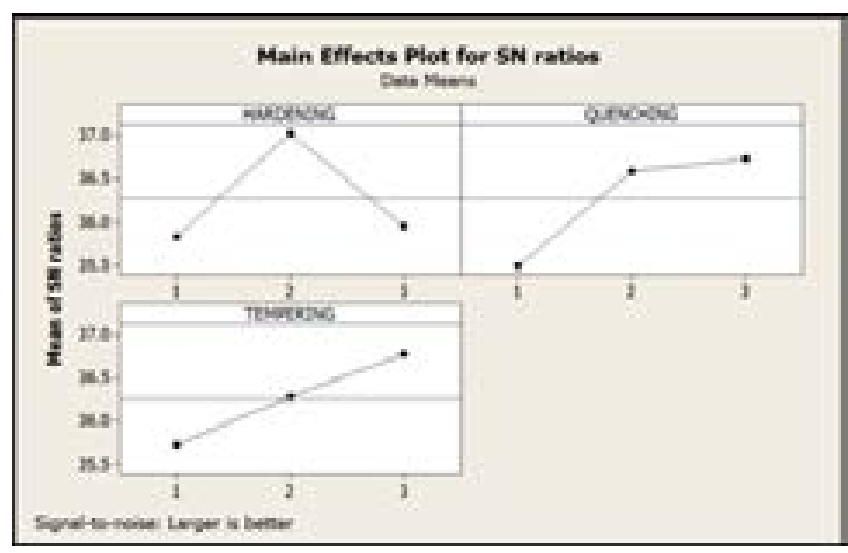

Figure 4. Mains effects plot for SN ratios (XW-42).

\section{Conclusion}

The various grades of tool steel group give the difference hardness (HRC). For the experiment, the optimum process parameter for XW- 5 and XW- 42 were determined respectively. As a comparison in the experiment between XW-5 and XW-42, XW-42 is the better and harder. The optimum condition for XW-5 is quenched at level 2 followed by hardening at level 1 . On the other hand, for XW-42 is hardening level 1, quenching level 3 and tempering level 3 .

In the experiment, XW-5 is recommended for applications demanding maximum wear resistance such as blanking and shearing tools for thin, hard material, long-run press tool and forming tools because of suitable hardness. Meanwhile, XW-42 is a versatile tool steel which can be used for a wide variety of cold work applications including blanking and other cutting processes and several forming processes.

\section{References}

1. Bała P. Microstructure characterization of high carbon alloy from Ni-Ta-Al-Co-Cr system. Archives of Metallurgy and Materials. 2012 Jan; 57(4):937- 41.

2. Alias M, Sakinah SMASA, Ariffin SZ, Zulkifli UM. The influence of the hardness on tool steel (DF-3 Assab steel) in heat treatment. Australian Journal of Basic and Applied Sciences. 2014 Mar; 8(4):423-7.

3. Dildin AN, Chumanov IV. Study of the processes of metal recovery from steel slags. Indian Journal of Science and Technology. 2015 Dec; 8(34):1-7.

4. Rafal D, Grzegorz C, Krzysztof W. Effect of the additional prior to heat treatment on the final properties of the steel. Proceedings of the 24th International Conference on Metallurgy and Materials; Brno, Czech Republic. 2015 Jun 3-5. p. 1-6.

5. Senthilkumar T, Ajiboye TK. Effect of heat treatment processes on the mechanical properties of medium carbon steel. Journal of Minerals and Materials Characterization and Engineering. 2012 Feb; 11(2):143-52.

6. Murugan VK, Mathews DP. Surface hardness behaviour of heat treated Ni-Cr-Mo alloys. International Journal of Engineering Science and Technology. 2012 Dec; 4(12):4739-44.

7. Bhateja A, Varma A, Kashyap A, Singh B. Study the effect on the hardness of the three sample grades of tool steel i.e. EN-31, EN-8 and D3 after heat treatment processes such as annealing, normalizing and hardening and tempering. International Journal of Engineering and Science. 2012; 1(2):253-9.

8. Dziurka R, Pacyna J, Tokarski T. Effect of heating rate on the phase transformations during tempering of low carbon Cr-Mn-Mo alloy steel. Archives of Materials Science and Engineering. 2013 Sep; 63(1):13-8.

9. Htun MS, Kyaw ST, Lwin KT. Effect of heat treatment on microstructures and mechanical properties of spring steel. Journal of Metals, Materials and Minerals. 2008; 18(2):1917.

10. Bashu SA, Singh K, Rawat MS. Effect of heat treatment on mechanical properties and fracture behaviour of a 12CrMoV steel. Materials Science and Engineering: A. 1990 Jul; 127(1):7-15.

11. Rajarasalnath S, Balasubramanian K. New algorithm to address confounding problems in Taguchi parameter design - A practical study. Indian Journal of Science and Technology. 2015 Dec; 8(35):1-7. 